\title{
Pemodelan Kepuasan Pengguna BRT Trans Jateng Koridor 1 Purwokerto - Purbalingga Dengan Metode Structural Equation Modelling
}

\author{
Faiq Muhammad Azka, Ketut Dewi Martha Erli Handayeni \\ Departemen Perencanaan Wilayah dan Kota, Institut Teknologi Sepuluh Nopember Surabaya \\ e-mail: faiqmuhammadazka@gmail.com
}

\begin{abstract}
Abstrak-Bus Rapid Transit (BRT) Trans Jateng Koridor 1 Purwokerto - Purbalingga mulai beroperasi pada Agustus 2018. Angkutan ini memiliki rata-rata $70 \%$ untuk angka keterisian (load factor). Melihat data tersebut, menjadikan BRT Trans Jateng Koridor 1 Purwokerto - Pubalingga sebagai transportasi umum yang memiliki potensi besar untuk dapat melayani perjalanan masyarakat di Kabupaten Banyumas dan Purbalingga. Studi ini bertujuan untuk mengembangkan model kepuasan pengguna terhadap layanan BRT Trans Jateng Koridor 1 Purwokerto - Purbalingga dengan metode analisis SEM (Structural Equation Modelling). Model ini dapat digunakan untuk mengevaluasi pengaruh aspek-aspek pelayanan BRT terhadap kepuasan pengguna. Hasil studi menunjukkan bahwa aspek operasional BRT serta aspek informasi dan komunikasi memiliki pengaruh positif yang siginifikan terhadap kepuasan pengguna. Aspek operasional BRT mencakup atribut kecepatan bus, pemungutan tarif, dan frekuensi layanan. Aspek informasi dan komunikasi mencakup atribut branding dan informasi penumpang. Pengembangan model kepuasan pengguna BRT dapat dimanfaatkan sebagai instrumen untuk mengevaluasi pelayanan BRT yang sesuai dengan harapan pengguna.
\end{abstract}

Kata Kunci-BRT, SEM, Trans Jateng

\section{PENDAHULUAN}

$\mathrm{P}$ erkembangan sebuah kota tidak dapat dipisahkan dari kegiatan yang berada di dalamnya. Kegiatan ekonomi dan sosial masyarakat di dalamnya menjadi penggerak sebuah kota untuk maju dan tumbuh. Berbagai kegiatan tersebut tidak dapat dipenuhi dalam suatu cakupan kawasan saja. Masing-masing kawasan baik di dalam maupun di luar kota tersebut saling berkaitan dan melengkapi. Perbedaan tata guna lahan dan peruntukan masing-masing kawasan mengakibatnya permintaan turunan (derived demand) berupa perpindahan orang, barang dan kendaraan. Perpindahan dari masing-masing kawasan tersebut menciptakan bangkitan dan tarikan pergerakan. Untuk menghubungkan antar kawasan dengan masing-masing fungsi diperlukan manajemen transportasi yang tepat. Manajemen transportasi merupakan usaha pengorganisasian transportasi untuk memindahkan orang dan barang secara efektif dan efisien [1]. Menurut data dari BPS Pusat, jumlah kendaraan bermotor di Indonesia pada tahun 2018 sebanyak 162.3 juta dengan komposisi 137.7 juta kendaraan roda 2, 15.8 juta roda 4 , dan 8.8 juta untuk bus dan truk. Angka ini hampir mencapai setengah dari jumlah populasi Indonesia.

Pemerintah pusat dan daerah mulai menginisiasi pengadaan transportasi masal untuk mengurangi jumlah penggunaan kendaraan pribadi sebagai salah satu bentuk manajemen transportasi yang berkelanjutan. Konsep transportasi masal yang banyak diprogramkan di Indonesia adalah dengan angkutan bus, atau yang lebih banyak dikenal dengan BRT (Bus Rapid Transit). BRT merupakan moda transportasi cepat dengan basis roda yang menggabungkan stasiun, kendaraan, pelayanan, lajur, dan ITS kedalam sistem yang terintegrasi dengan identitas positif yang membangkitkan pandangan yang unik. BRT didesain untuk dapat menyesuaikan dengan pasar yang dituju dan keadaan fisik di dalamnya, sehingga dapat diimplementasi dengan berbagai macam keadaan [2]. Pengertian lain dari BRT yaitu merupakan moda transportasi yang mengacu pada pengaplikasian infrastruktur dan operasional berbasis seperti rel kepada sistem bus dengan harapan dapat memberikan pelayanan tingkat tinggi, lajur yang khusus, stasiun, dan ITS (Intelligent Transport System) dengan biaya lebih kecil dari kendaraan berbasis rel [3].

Awalnya BRT merupakan program Kota Curitiba, Brazil yang diinisiasi oleh wali kota Jaime Lerner. Keberhasilan penerapan BRT di Curitiba menginspirasi kota di negara lain untuk menerapkan konsep transportasi masal ini termasuk di Jakarta dengan layanan Trans Jakarta. Kelebihan yang ditawarkan dengan menerapkan konsep BRT adalah layanan yang lebih fleksibel dibandingkan dengan kereta. Pelayanan BRT dapat mengikuti bentuk morfologi kota yang dapat menjangkau area pemukiman dengan layanan pengumpan (feeder) [4]. Dalam segi pelayanan, indikator utama dari performa BRT adalah dari segi kecepatan, kapasitas, dan produktivitas [5].

Dinas Perhubungan Provinsi Jawa Tengah meresmikan layanan BRT (Bus Rapid Transit) Trans Jateng dengan koridor pertama di Kota Semarang pada bulan Juli 2017. Layanan BRT Trans Jateng merupakan program Dinas Perhubungan Jawa Tengah mengembangkan 24 koridor yang bertujuan menghubungkan kawasan-kawasan pembangkit di Jawa Tengah.

Pada bulan Agustus 2018 Pemerintah Provinsi Jawa Tengah meluncurkan koridor kedua BRT Trans Jateng dengan rute Purwokerto - Purbalingga. Dalam waktu satu tahun setelah beroperasi, layanan BRT Trans Jateng Koridor 1 Purwokerto - Purbalingga telah melayani kebutuhan tranportasi masyarakat Banyumas dan Purbalingga dengan angka keterisian (load factor) rata-rata sebesar 70\%. Angka keterisian (load factor) yang cukup tinggi menandakan minat yang tinggi dari masyarakat Purwokerto dan Purbalingga untuk menggunakan layanan BRT Trans Jateng Koridor 1 Purwokerto - Purbalingga. Koridor tersebut menjadi satu dari tiga koridor yang sudah berjalan saat ini.

Dalam pengembangan layanan BRT Trans Jateng diperlukan penambahan dan perbaikan layanan serta 
evaluasi agar menjadi masukan untuk kebijakan pengembangan BRT Trans Jateng kedepannya. Penelitian ini bertujuan menghasilkan evaluasi penyediaan layanan BRT Trans Jateng Koridor 1 Purwokerto - Purbalingga dengan output berupa pemodelan berdasarkan kepuasan pengguna.

\section{METODE PENELITIAN}

A. Metode

Penelitian ini merupakan penelitian dengan jenis kuantitatif yang berlandaskan pada filsafat positivisme. Metode ini digunakan untuk meneliti populasi atau sampel tertentu dengan teknik pengambilan sampel secara acak (random). Pengumpulan data pada metode kuantitatif menggunakan instrumen penelitian, dengan tujuan untuk menguji hipotesis yang telah ditetapkan [6]. Beberapa ciri khas pendekatan kuantitatif adalah mengacu pada pengumpulan dan analisis data kuantitatif (berupa angka/ numerik), menggunakan strategi survei dan eksperimen, menggunakan sampel dengan ukuran besar, serta pengujian teori dengan uji-uji statistik. Pemodelan kepuasan pengguna BRT Trans Jateng Koridor 1 Purwokerto - Purbalingga menghasilkan data besarnya perhitungan aspek dan atribut yang berpengaruh terhadap pelayanan sistem BRT ditinjau dari perspektif penumpang.

Penelitian ini menggunakan teknik analisis Structural Equation Modelling (SEM) yang bersifat sangat crosssectional, linear, dan umum. SEM adalah penggabungan dari analisis faktor, analisis jalur (path analysis), dan regresi. SEM dapat digunakan untuk menguji dan membangun model statistik dalam bentuk model sebabakibat [7].

SEM dapat dikatakan sebagai metode analisis lanjutan dari analisis regresi karena mempertimbangkan pemodelan interaksi, nonlinearitas variabel-variabel bebas yang berkorelasi, kesalahan pengukuran/ eror, serta beberapa variabel laten. Oleh karena itu, SEM dapat disimpulkan berfungsi sebagai alternatif yang lebih kuat dibandingkan analisis regresi berganda, analisis jalur, analisis faktor, analisis time series, dan analisis kovarian secara terpisah. Beberapa langkah dalam melakukan pemodelan menggunakan SEM:

1. Merumuskan variabel yang akan diuji. Variabel didapatkan dari studi literatur dan penelitian terdahulu;

2. Menentukan skema analisis jalur (path analysis) dari variabel yang dapat diuji dan variabel laten; dan

3. Memodelkan skema dengan input berupa hasil kuisioner.

Analisis SEM menggunakan diagram jalur (path analysis) yang menunjukkan pola hubungan antar variabel. Pola hubungan antar variabel diisi dengan variabel yang diobservasi, variabel laten, dan indikator. Data yang digunakan dalam analisis SEM merupakan indikator dan variabel yang telah ditanyakan kepada responden dengan bentuk kuisioner. Penelitian ini menghasilkan analisis jalur sebagai berikut:

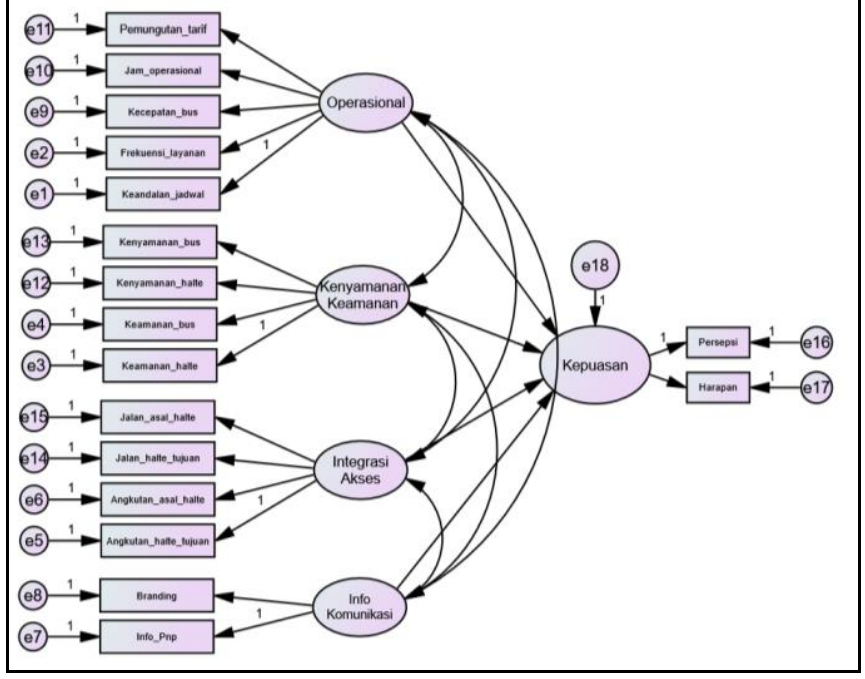

Gambar 1. Path Analysis

Model analisis jalur yang digunakan dalam penelitian ini seperti yang terdapat pada gambar 1. Variabel laten eksogen terdiri dari aspek operasional, kenyamanan \& keamanan, integrasi \& akses, dan informasi \& komunikasi. Sedangkan variabel laten endogen adalah kepuasan. Hubungan antara variabel laten memiliki persamaan masing-masing. Hubungan antara variabel laten eksogen terhadap variabel laten endogen dituliskan dengan notasi $\gamma$ (gamma) sedangkan antar variabel laten endogen dituliskan dengan notasi $\beta$ (beta).

Persamaan dasar yang digunakan dalam SEM adalah sebagai berikut:

Keterangan:

$\begin{array}{ll}\eta \text { (eta) } & \text { : variabel laten endogen } \\ \xi \text { (xi) } & \text { : variabel laten eksogen } \\ \zeta \text { (zeta) } & \text { : besaran variabel eror }\end{array}$

$\beta$ (beta) \& $\gamma$ (gamma) : besar koefisen structural

Penelitian ini menggunakan 17 variabel yang terdiri dari 15 variabel atribut pelayanan dan 2 variabel atribut kepuasan pengguna. Variabel tersebut dikelompokkan dalam 5 aspek. Masing-masing variabel diberikan notasi untuk mempermudah pengoperasionalan teknik analisis SEM.

\begin{tabular}{|c|c|c|}
\hline Aspek & Atribut & Notasi SEM \\
\hline \multirow[t]{5}{*}{ Operasional } & Sistem pembayaran & $\mathrm{X} 11$ \\
\hline & Jam operasional & $\mathrm{X} 12$ \\
\hline & Kecepatan bus & $\mathrm{X} 13$ \\
\hline & Frekuensi layanan & $\mathrm{X} 14$ \\
\hline & Keandalan jadwal & $\mathrm{X} 15$ \\
\hline \multirow{4}{*}{$\begin{array}{l}\text { Kenyamanan } \\
\text { dan Keamanan }\end{array}$} & Kenyamanan di dalam bus & $\mathrm{X} 21$ \\
\hline & Kenyamanan di halte & $\mathrm{X} 22$ \\
\hline & Keamanan di dalam bus & $\mathrm{X} 23$ \\
\hline & Keamanan di halte & $\mathrm{X} 24$ \\
\hline \multirow[t]{4}{*}{$\begin{array}{l}\text { Akses } \\
\text { Integrasi }\end{array}$} & $\begin{array}{l}\text { Akses jalan kaki dari tempat asal ke } \\
\text { halte }\end{array}$ & $\mathrm{X} 31$ \\
\hline & $\begin{array}{l}\text { Akses jalan kaki dari halte ke } \\
\text { tempat tujuan }\end{array}$ & $\mathrm{X} 32$ \\
\hline & $\begin{array}{l}\text { Integrasi angkutan umum dari } \\
\text { tempat asal ke halte }\end{array}$ & $\mathrm{X} 33$ \\
\hline & $\begin{array}{l}\text { Integrasi angkutan umum dari halte } \\
\text { ke tempat tujuan }\end{array}$ & X34 \\
\hline \multirow{2}{*}{$\begin{array}{l}\text { Komunikasi } \\
\text { dan Informasi }\end{array}$} & Promosi & $\mathrm{X} 41$ \\
\hline & Informasi penumpang & $\mathrm{X} 42$ \\
\hline \multirow[t]{2}{*}{ Kepuasan } & Persepsi & $\mathrm{Y} 1$ \\
\hline & Harapan & Y2 \\
\hline
\end{tabular}

Sumber: [8], [9], [10], [11] 


\section{B. Pengumpulan Data}

Penelitian dilakukan Kabupaten Banyumas dan Purbalingga, tepatnya pada sepanjang koridor 1 BRT Trans Jateng Purwoketo - Purbalingga. Pengambilan data berupa kuisioner dengan total 170 responden yang dilakukan dengan cara primer. Yaitu metode untuk memperoleh data secara langsung dari obyek penelitian. Metode pengumpulan data survei dilakukan dengan cara oberservasi langsung dan kuisioner. Observasi dilakukan untuk melihat kondisi pelayanan BRT Trans Jateng secara langsung dari perspektif pengguna. Observasi dilakukan dengan berfokus pada atribut yang telah ditentukan sebelumnya. Sedangkan kuisioner berisi atribut-atribut yang telah ditentukan sebelumnya dan dinilai oleh responden dengan skala likert 1 hingga 10 untuk mengetahui pelayanan BRT Trans Jateng. Survei dilaksakan dengan metode onboard, atau survei di dalam angkutan dan di halte-halte pada Koridor 1 Purwokerto - Purbalingga.

\section{HASIL DAN DISKUSI}

\section{A. Pengembangan Model}

Mengacu pada analisis jalur yang terbentuk, penggunaan teknik analisis SEM pada penelitian ini menghasilkan 4 hipotesis:

1. Aspek operasional berpengaruh terhadap kepuasan pengguna;

2. Aspek kenyamanan dan keamanan berpengaruh terhadap kepuasan pengguna;

3. Aspek integrasi dan akses berpengaruh terhadap kepuasan pengguna; dan

4. Aspek komunikasi dan informasi berpengaruh terhadap kepuasan pengguna.

Perhitungan SEM harus mencari model fit sebelum dapat dilakukan pengambilan kesimpulan dari hipotesis-hipotesis yang diajukan. Model fit tersebut mengikuti ketentuan dari analisis CFA (Confirmatory Factor Analysis) seperti yang terdapat pada tabel 2:

\begin{tabular}{lc}
\multicolumn{2}{c}{ Tabel 2. Kriteria CFA } \\
\hline \hline \multicolumn{1}{c}{ Kriteria } & Cut of Value \\
\hline CMIN & $<2$ \\
Probabilitas & $>0,05$ \\
\hline \hline Sumber: [12] & \\
Dalam CFA semua model dihubungakan dengan garis
\end{tabular}

Dalam CFA semua model dihubungakan dengan garis kovarians untuk menguji hubungan antar variabel laten seperti yang terdapat pada gambar 2 .

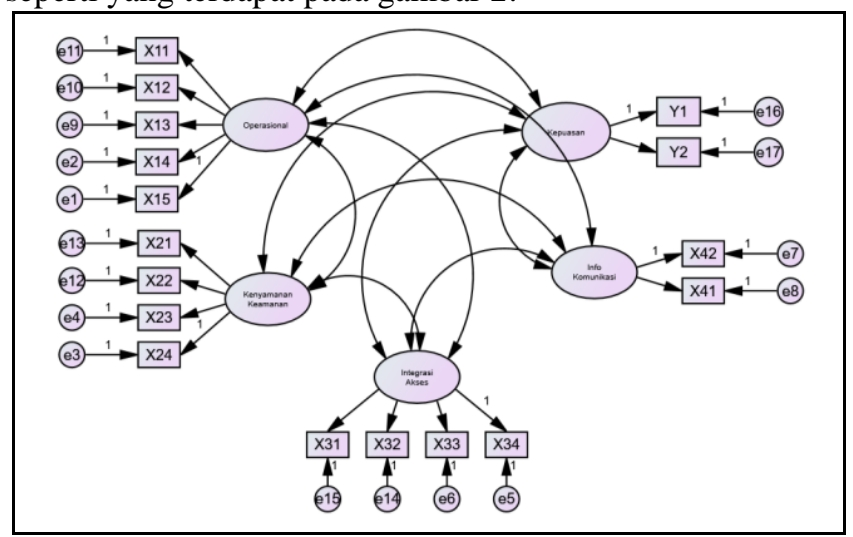

Gambar 2. Pengujian CFA

Dalam menjalankan analisis, sering kali model konstrak yang diajukan belum memenuhi kriteria. Beberapa cara dilakukan untuk mengasilkan model yang fit, salah satu yang langkah yang dapat dijalankan adalah dengan menambah jumlah sampel. Sampel yang disarankan berkisar antara 1.000-2.500 responden [7]. Namun cara ini memiliki tingkat kesulitan yang tinggi karena harus menambah jumlah sampel yang tidak sedikit. Cara lain dalam menghasilkan model yang fit adalah mereduksi jumlah variabel terobservasi pada beberapa variabel laten. Metode ini digunakan untuk mengurangi variabel yang memiliki data outlier.

Untuk menentukan atribut yang harus direduksi, dapat dilihat dari tabel modification indices dengan angka yang tertinggi dan terbanyak. Untuk menghasilkan model yang fit, dilakukan reduksi beberapa atribut, yaitu: jam operasional (X12) dan keandalan jadwal (X15) pada aspek operasional, kenyamanan di dalam bus (X21) dan keamanan di dalam bus (X23) pada aspek kenyamanan dan keamanan, dan angkutan umum tempat asal ke halte (X33), dan angkutan umum tempat halte ke tempat tujuan (X34). Tabel 3 menunjukkan output CFA setelah dilakukan reduksi. Model sudah dikatakan fit karena memiliki probabilitas lebih dari 0,05 dan nilai CMIN kurang dari 2. Tabel 3. Output CFA

\begin{tabular}{lrrrrr}
\hline \multicolumn{1}{c}{ Model } & NPAR & CMIN & DF & P & CMIN/DF \\
\hline $\begin{array}{l}\text { Default Model } \\
\text { Saturated Model }\end{array}$ & 32 & 47,927 & 34 & 0,057 & 1,410 \\
Independence Model & 66 & 0,000 & 0 & & \\
\hline \hline
\end{tabular}

\section{B. Pengujian Model Kepuasan}

Model akhir perhitungan SEM seperti yang dijelaskan pada gambar 3 dengan atribut yang telah direduksi untuk menghasilkan model yang fit. Terdapat pengurangan jumlah atribut dari 17 menjadi 11. Masing-masing variabel laten dihubungkan kembali seperti pada model awal (gambar 1).

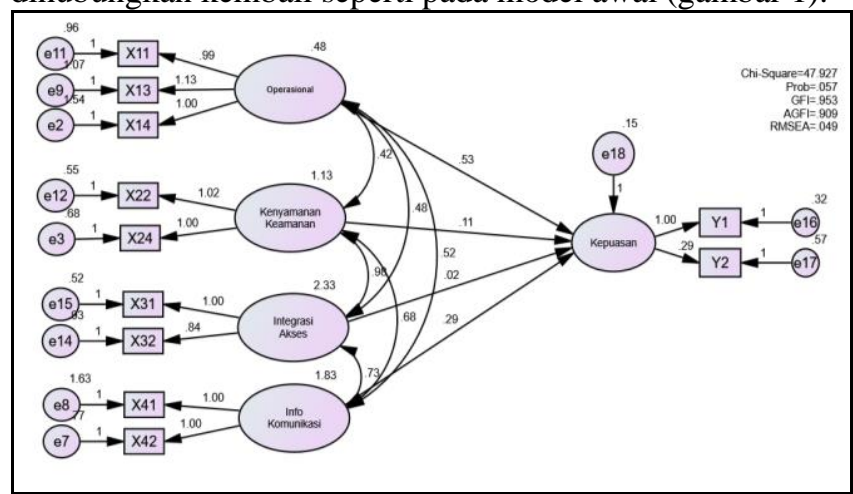

Gambar 3. Model Akhir SEM

Perhitungan model SEM yang dilakukan selanjutnya dilakukan pengujian kriteria goodness of fit untuk menguji bentuk model yang digunakan dengan kriteria-kriteria tertentu. Kriteria ini merupakan pengujian yang dilakukan juga pada analisis CFA (Confirmatory Factor Analysis). Pada kriteria Chi Square didapatkan hasil sebesar 47,927. Hasil tabel hitung chi square dengan degree of freedom 34 dan eror 5\% adalah 48,602367. Perhitungan Chi Square lebih kecil dari tabel, maka dengan itu model sudah fit.

Kriteria lain seperti CMIN mendapat hasil 1,410 lolos kriteria fit karena memiliki nilai $<2$. Probabilitas bernilai 0,057 lolos kriteria fit karena $>0,05$. RMSEA bernilai 0,49 memiliki kriteria fit karena $\leq 0,08$. Kriteria ECVI dan AIC lolos kriteria fit karena kedua nilai tersebut lebih kecil 
dibandingkan dengan ECVI dan AIC saturated model \& independence model. Nilai GFI, AGFI, PGFI, CFI, dan TLI sebesar 0,953; 0,909; 0,491; dan 0,976 secara berurutan. Kelima kriteria ini dapat dikatakan fit apabila memiliki nilai $>0,9$. Kesimpulan yang didapat dari Goodness of Fit model dapat dilakukan perhitungan selanjutnya karena telah memenuhi kriteria-kriteria umum yang ditetapkan (Sarwono, 2010).

\begin{tabular}{|c|c|c|c|}
\hline Kriteria & Cut of Value & Hasil & Ket \\
\hline Chi Square & $<$ chi square tabel & 47,927 & $\sqrt{ }$ \\
\hline CMIN & $<2$ & 1,410 & $\sqrt{ }$ \\
\hline Probabilitas & $>0,05$ & 0,057 & $\sqrt{ }$ \\
\hline RMSEA & $\leq 0,08$ & 0,049 & $\sqrt{ }$ \\
\hline ECVI & $\begin{array}{l}<\text { ECVI Sat. Model and Ind } \\
\text { Model }\end{array}$ & $\begin{array}{l}0,662 ; \\
0,781 \text { (Sat } \\
\text { model); } \\
3,838 \text { (Ind } \\
\text { model) }\end{array}$ & $\sqrt{ }$ \\
\hline AIC & $\begin{array}{l}<\text { AIC Sat Model \& Ind } \\
\text { Model }\end{array}$ & $\begin{array}{l}\text { 111,927; } \\
132 \text { (Sat model); } \\
648,703 \text { (Ind } \\
\text { model) }\end{array}$ & $\sqrt{ }$ \\
\hline GFI & $>0,9$ & 0,953 & $\sqrt{ }$ \\
\hline AGFI & $>0,9$ & 0,909 & $\sqrt{ }$ \\
\hline CFI & $>0,9$ & 0,976 & $\sqrt{ }$ \\
\hline TLI & $>0,9$ & 0,961 & $\sqrt{ }$ \\
\hline
\end{tabular}

\section{Regression Weights}

Pengujian hipotesis yang diajukan melihat kriteria pada tabel regression weights. Hipotesis yang diterima (signifikan), harus memiliki nilai nilai C.R>1,96 dan $\mathrm{P}<0,05$. CR (critical ratio) merupakan rasio deviasi tertentu dari nilai rata-rata standar deviasi dan diperoleh dari estimasi parameter dibagi dengan standar eror [7]. Untuk pembobotan dengan signifikansi sebesar 0,05 nilai CR harus $>$ 1,96 agar dapat dikatakan memiliki hubungan yang signifikan (hipotesis diterima). Nilai P (probabilitas) dalam sebuah model dapat dikatakan diterima apabila $<0,05$. Tabel 5. Uji Hipotesis

\begin{tabular}{cccc}
\hline \hline Hipotesis & C.R. & P & Ket \\
\hline 1 & 2,527 & 0,011 & diterima \\
2 & 1,038 & 0,299 & tidak diterima \\
3 & 0,344 & 0,731 & tidak diterima \\
4 & 3,777 & $* * *$ & diterima \\
\hline \hline
\end{tabular}

Hasil perhitungan pada konstrak analisis jalur yang dibangun menunjukan terdapat dua hubungan yang signifikan antara variabel laten, yaitu operasional $\rightarrow$ kepuasan, dan info komunikasi $\rightarrow$ kepuasan. Kedua hubungan variabel ini dikatakan signifikan karena memiliki nilai $C R>1,96$ dan $\mathrm{P}<0,05$. Sedangkan untuk dua variabel lain tidak dapat dikatakan memiliki hubungan karena tidak memenuhi syarat, yaitu kenyamanan \& keamanan $\rightarrow$ kepuasan, dan integrasi akses $\rightarrow$ kepuasan. Dari 4 hipotesis yang diajukan pada awal penelitian, hanya dua yang dapat diterima, yaitu hipotesis 1 dan hipotesis 4, yaitu:

1. Aspek operasional pada BRT Trans Jateng berpengaruh terhadap kepuasan pengguna (hipotesis
$1)$

2. Aspek komunikasi dan informasi berpengaruh terhadap kepuasan pengguna (hipotesis) 4).

\section{Standardized Regression Weights}

Standar regression weight merupakan perhitungan untuk melihat besarnya dampak yang diberikan antara variabel satu dan variabel lainnya.

Tabel 6. Standardized Regression Weights

\begin{tabular}{ll}
\hline \multicolumn{1}{c}{ Hubungan Varibel } & Estimate \\
\hline Operasional $\rightarrow$ Kepuasan & 0,428 \\
Kenyamanan Keamanan $\rightarrow$ Kepuasan & 0,135 \\
Integrasi Akses $\rightarrow$ Kepuasan & 0,036 \\
Info Komunikasi $\rightarrow$ Kepuasan & 0,461 \\
Operasional $\rightarrow$ X11 & 0,572 \\
Operasional $\rightarrow$ X13 & 0,602 \\
Operasional $\rightarrow$ X14 & 0,486 \\
Info Komunikasi $\rightarrow$ X41 & 0,726 \\
Info Komunikasi $\rightarrow$ X42 & 0,839 \\
Kepuasan $\rightarrow$ Y1 & 0,838 \\
Kepuasan $\rightarrow$ Y2 & 0,318 \\
\hline \hline
\end{tabular}

Pada hipotesis 1, aspek operasional berpengaruh sebesar 0,428 satuan kepada faktor kepuasan pengguna BRT Trans Jateng. Dan aspek informasi dan komunikasi berpengaruh sebesar 0,461 satuan kepada kepuasan. Meskipun aspek kenyamanan \& keamanan dan integrasi \& akses memberikan pengaruh sebesar 0,135 dan 0,036 satuan kepada faktor kepuasan, tetapi kedua aspek tersebut tidak berpengaruh secara signifikan karena tidak lolos kriteria pada uji Critical Ratio dan Probabilitas.

Dalam aspek operasional, atribut yang memiliki pengaruh paling besar adalah kecepatan bus $\left(\mathbf{X}_{13}\right)$ dengan pengaruh sebesar 0,602. Kemudian atribut pemungutan tarif $\left(\mathbf{X}_{\mathbf{1 1}}\right)$ dengan pengaruh sebesar 0,572 dan atribut frekuensi layanan (X14) sebesar 0,486. Ketiga atribut ini memberikan pengaruh yang positif terhadap aspek operasional. Atribut branding $\left(\mathbf{X}_{41}\right)$ memberikan dampak sebesar 0,726 kepada aspek informasi dan komunikasi. Sedangkan informasi penumpang $\left(\mathbf{X}_{\mathbf{4 2}}\right)$ memberikan pengaruh sebesar 0,839 kepada aspek tersebut.

Untuk atribut pada aspek kenyamanan \& keamanan serta akses \& integrasi semua memiliki dampak yang positif kepada masing-masing aspek. Namun tidak dapat dijadikan sebagai pengukuran karena hubungan antara aspek tersebut tidak signifikan kepada kepuasan.

Aspek kepuasan dipengaruh paling besar oleh persepsi pengguna saat ini sebesar 0,838. Sedangkan harapan pengguna berperan sebesar 0,318 dalam menentukan kepuasan pengguna. 


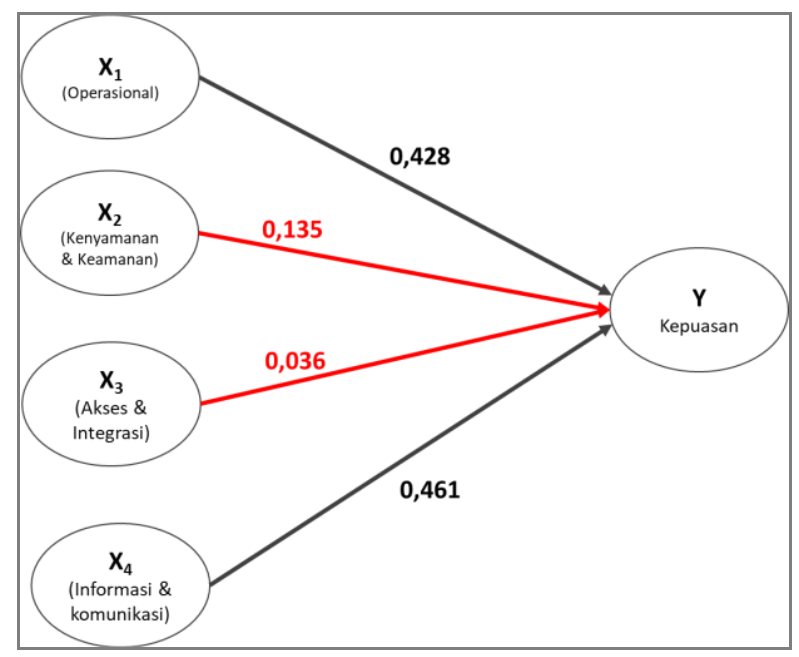

Gambar 4. Diagram Jalur Akhir

\section{E. Efek}

Efek merupakan pengaruh yang diberikan antara variabel baik secara langsung dan tidak langsung. Dalam efek dapat dihitung pengaruh sebuah observed variabel terhadap variabel laten dan sebaliknya. Efek langsung merupakan efek yang muncul apabila variabel berhubungan secara langsung, dalam model diagram jalur diwujudkan dengan garis hubungan. Sedangkan efek tidak langsung merupakan efek yang muncul dari variabel satu ke variabel lain dengan terlebih dahulu melewati perantara. Penjumlahan efek langsung dan efek tidak langsung menghasilkan efek total yang merupakan perhitungan keseluruhan dari hubungan antar variabel. Berikut merupakan tabel efek total:

Tabel 7. Efek Total

\begin{tabular}{|c|c|c|c|c|c|}
\hline & $\left(\mathbf{X}_{1}\right)$ & $\left(\mathbf{X}_{2}\right)$ & $\left(\mathbf{X}_{3}\right)$ & $\left(\mathbf{X}_{4}\right)$ & (Y) \\
\hline Kepuasan (Y) & 0.428 & 0.135 & 0.036 & 0.461 & 0 \\
\hline $\mathrm{Y} 2$ & $\overline{0.136}^{a}$ & 0.043 & 0.011 & $\overline{0.146}^{c}$ & $\underline{0.318}$ \\
\hline $\mathrm{Y} 1$ & 0.359 & 0.113 & 0.03 & $\overline{0.386}^{\mathrm{d}}$ & $\underline{0.838}$ \\
\hline $\mathrm{X} 31$ & 0 & 0 & 0.904 & 0 & 0 \\
\hline X32 & 0 & 0 & 0.799 & 0 & 0 \\
\hline $\mathrm{X} 22$ & 0 & 0.826 & 0 & 0 & 0 \\
\hline $\mathrm{X} 11$ & 0.572 & 0 & 0 & 0 & 0 \\
\hline $\mathrm{X} 13$ & 0.602 & 0 & 0 & 0 & 0 \\
\hline X41 & 0 & 0 & 0 & 0.726 & 0 \\
\hline $\mathrm{X} 42$ & 0 & 0 & 0 & 0.839 & 0 \\
\hline $\mathrm{X} 24$ & 0 & 0.789 & 0 & 0 & 0 \\
\hline $\mathrm{X} 14$ & 0.486 & 0 & 0 & 0 & 0 \\
\hline
\end{tabular}

Aspek pelayanan BRT Trans Jateng memiliki pengaruh yang besar terhadap peningkatan kepuasan pengguna baik secara langsung maupun tidak langsung. Secara langsung, apabila aspek pelayanan ditingkatkan, maka kepuasan juga akan meningkat. Secara tidak langsung, peningkatan aspek pelayanan akan meningkatkan persepsi dan harapan pengguna BRT Trans Jateng.

Efek langsung diberikan aspek kepuasan terhadap persepsi dan harapan sebesar 0,838 dan 0,318 apabila kepuasan ditingkatkan sebesar 1 satuan. Persepsi dan harapan pengguna BRT Trans Jateng terhadap layanan dapat ditingkatkan dengan menambah/memperbaiki aspek operasional dan informasi \& komunikasi. Persepsi pengguna terhadap layanan BRT Trans Jateng dapat ditingkatkan sebesar 0,359 satuan apabila meningkatkan operasional sebanyak 1 satuan, dan dapat ditingkatkan sebesar 0,386 satuan dengan meningkatkan informasi \& komunikasi sebesar 1 satuan. Harapan pengguna terhadap layanan BRT Trans Jateng dapat ditingkatkan sebesar 0,136 satuan jika meningkatkan aspek operasional sebesar 1 satuan, dan dapat ditingkatkan 0,146 satuan jika meningkatkan aspek informasi \& komunikasi sebesar 1 satuan.

\section{F. Model Akhir}

Model akhir yang dapat dibangun dari hubungan antara variabel-variabel tersebut dijelaskan dengan pemodelan berikut:

$$
Y=0,428 X_{1}+0,461 X_{4}
$$

\section{Keterangan:}

$\mathbf{Y}=$ kepuasan

$\mathbf{X}_{\mathbf{1}}=$ operasional

$\mathbf{X}_{\mathbf{4}}=$ informasi \& komunikasi

Dari pemodelan di atas, dapat diketahui bahwa setiap kenaikan aspek operasional sebanyak 1 satuan, akan meningkatkan tingkat kepuasan pegguna terhadap pelayanan BRT Trans Jateng sebesar 0,428 satuan. Serta kenaikan aspek informasi \& komunikasi sebanyak 1 satuan, akan meningkatkan tingkat kepuasan pegguna terhadap pelayanan BRT Trans Jateng sebesar 0,461 satuan.

\section{KESIMPULAN}

Berdasarkan hasil analisis Structural Equation Modelling (SEM), terdapat 2 aspek yang berpengaruh terhadap kepuasan pengguna BRT Trans Jateng Koridor 1 Purwokerto - Purbalingga. Aspek tersebut adalah operasional dan informasi \& komunikasi. Sedangkan 2 aspek lain tidak memiliki pengaruh signifikan yaitu kenyamanan \& keamanan dan akses \& integrasi. Evaluasi ini diwujudkan dengan rumus akhir sebagai berikut:

\section{Keterangan:}

$$
Y=0,428 X_{1}+0,461 X_{4}
$$

$$
\begin{array}{ll}
\mathbf{Y} & =\text { kepuasan } \\
\mathbf{X}_{\mathbf{1}} & =\text { operasional } \\
\mathbf{X}_{\mathbf{4}} & =\text { informasi \& komunikasi }
\end{array}
$$

Artinya, setiap kenaikan sebesar 1 satuan pada aspek operasional akan meningkatkan kepuasan sebesar 0,428 satuan. Begitu juga dengan peningkatan 1 satuan pada aspek informasi \& komunikasi akan meningkatkan kepuasan sebesar 0,461 satuan.

Dari aspek operasional, atribut yang paling berpengaruh dalam peningkatan kepuasan pengguna adalah sebagai berikut: kecepatan bus $(0,603)$, pemungutan tarif $(0,572)$, dan frekuensi layanan $(0,486)$. Sedangkan pada aspek informasi \& komunikasi, atribut yang berpengaruh adalah: branding/promosi $(0,726)$, dan informasi penumpang $(0,839)$. Atribut kecepatan bus memiliki pengaruh yang paling besar terhadap aspek operasional, sedangkan atribut informasi penumpang memiliki pengaruh terbesar pada aspek informasi \& komunikasi. Sehingga, untuk meningkatkan kepuasan pengguna, kedua atribut tersebut dapat menjadi rekomendasi utama bagi pihak pengelola BRT Trans Jateng untuk ditingkatkan pelayanannya.

Berdasarkan hasil penelitian, saran yang diberikan kepada Dinas Perhubungan Jawa Tengah untuk meningkatkan pelayanan BRT Trans Jateng dapat difokuskan pada atribut dengan pengaruh terbesar pada dua aspek yang signifikan, operasional dan informasi \& komunikasi. Terutama pada atribut kecepatan bus dan informasi penumpang. Namun atribut lain pada aspek operasional dan informasi \& komunikasi juga perlu mendapat perhatian karena memiliki pengaruh yang positif terhadap peningkatan kepuasan 
pengguna.

\section{DAFTAR PUSTAKA}

[1] Nasution, M. N. (2004). Manajemen Transportasi. Jakarta: Penerbit Ghalia Indonesia.

[2] Levinson, H. (2003). Bus Rapid Transit Volume I. Washington DC: Transit Cooperative Research Program.

[3] Currie, G., \& Delbosc., A. (2011). Understanding bus rapid transit route ridership drivers : An empirical study of Australian BRT systems. Transport Policy, 755-764.

[4] Nikitas, A., \& Karlsson, M. (2015). A Worldwide State-of-the-Art Analysis for Bus Rapid Transit:. Journal of Public Transportation.

[5] Hidalgo, D., \& Gutierrez, L. (2013). BRT and BHLS around the world: Explosive growth large positive impacts and many issues outstanding. Research in Transportation Economics, 8-13.

[6] Sugiyono. (2016). Metode Penelitian Kuantitatif, Kualitatif dan R\&D. Bandung: PT Alfabet.

[7] Sarwono, J. (2010). Pengertian Dasar Strucural Equation Modelling. Jurnal Ilmiah Manajemen Bisnis, 173-182.

[8] ITDP. (2016). BRT Standard. ITDP

[9] Deng, T., \& Nelson, J. D. (2011). Recent developments in bus rapid transit: A review of the literature. Transport Review, 69-96

[10] Cervero, R. (2013). Bus Rapid Transit (BRT) An Efficient and Competitive Mode of Public Transport. Berkeley, USA: University of California

[11] Galicia, L. D., \& Cheu, R. L. (2009). Bus Rapid Transit Features and Deployment Phases for U.S. Citie. Journal of Public Transportation, 23-38.

[12] Hair, J. F., Black, W. C., Babin, B. J., \& Anderson, R. E. (2010). Multivariate Data Analysis. Boston: Pearson 